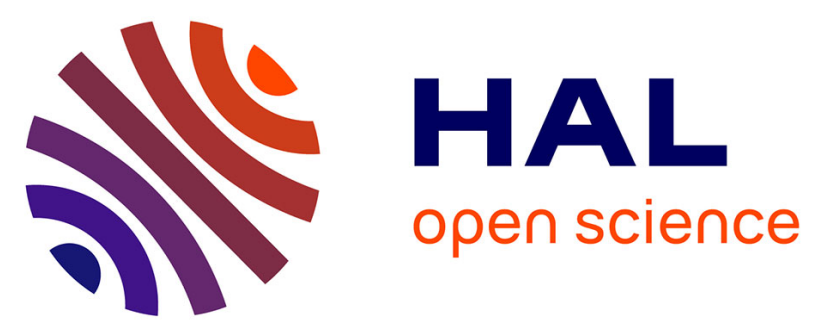

\title{
Cross-section measurements of krypton 78 to 86 isotopes in the spallation of palladium and silver. A new semi-empirical spallation formula in the $\mathrm{Y}$ to $\mathrm{Ag}$ target mass region
}

B. Lavielle, S. Regnier

\section{- To cite this version:}

B. Lavielle, S. Regnier. Cross-section measurements of krypton 78 to 86 isotopes in the spallation of palladium and silver. A new semi-empirical spallation formula in the $\mathrm{Y}$ to $\mathrm{Ag}$ target mass region. Journal de Physique, 1984, 45 (6), pp.981-988. 10.1051/jphys:01984004506098100 . jpa-00209842

\section{HAL Id: jpa-00209842 https://hal.science/jpa-00209842}

Submitted on 1 Jan 1984

HAL is a multi-disciplinary open access archive for the deposit and dissemination of scientific research documents, whether they are published or not. The documents may come from teaching and research institutions in France or abroad, or from public or private research centers.
L'archive ouverte pluridisciplinaire HAL, est destinée au dépôt et à la diffusion de documents scientifiques de niveau recherche, publiés ou non, émanant des établissements d'enseignement et de recherche français ou étrangers, des laboratoires publics ou privés. 
Classification

Physics Abstracts

$25.40-27.50-27.60-94.40$

\title{
Cross-section measurements of krypton 78 to 86 isotopes in the spallation of palladium and silver. A new semi-empirical spallation formula in the $Y$ to Ag target mass region
}

\author{
B. Lavielle and S. Regnier \\ Centre d'Etudes Nucléaires de Bordeaux-Gradignan, \\ Laboratoire de Chimie Nucléaire, E.R.A. n 144,33170 Gradignan, France
}

(Reçu le 27 janvier 1984, accepté le 20 février 1984)

\begin{abstract}
Résumé. - La composante " cosmogénique " du krypton dans les météorites de fer est due aux réactions nucléaires induites par le rayonnement cosmique primaire ou secondaire dans des cibles allant de $\operatorname{Zr}(Z=40)$ à $\operatorname{Pd}(Z=46)$. Nous avons mesuré, par spectrométrie de masse de haute sensibilité, les sections efficaces des réactions nucléaires conduisant à ${ }^{78-86} \mathrm{Kr}$ dans des cibles de $\mathrm{Pd}$ et $\mathrm{Ag}$ bombardées par des protons de 0,15, 0,6, 1,05 et $24 \mathrm{GeV}$. Ces nouvelles mesures et celles existant dans la littérature entre $\mathrm{Y}$ et $\mathrm{Ag}$ nous ont permis de modifier sensiblement les paramètres de la formule de Rudstam dans cette région de cibles. Sur 500 sections efficaces expérimentales, notre formule permet d'en calculer $89 \%$ à mieux qu'un facteur 2 si on considère les produits tels que $5 \leqslant \Delta A \leqslant 40$ et les énerrgies incidentes telles que $E_{\mathrm{p}} \geqslant 130 \mathrm{MeV}$. Si on élimine les énergies $E_{\mathrm{p}} \leqslant 206 \mathrm{MeV}$ et les petites sections efficaces $\sigma \leqslant 0,1 \mathrm{mb}$, ce pourcentage s'élève à plus de $96 \%$. Notre formule convient donc au calcul des sections efficaces non mesurées de ${ }^{78-84} \mathrm{Kr}$ dans $\mathrm{Mo}$, Ru et $\mathrm{Rh}$, cibles dont la contribution au krypton cosmogénique dans les météorites de fer est dominante.
\end{abstract}

\begin{abstract}
Cosmogenic krypton in iron meteorites arises from the bombardment of the elements between $\operatorname{Zr}(Z=40)$ and $\operatorname{Pd}(Z=46)$ by primary and secondary cosmic rays. In this work we measured the cross-sections of ${ }^{78-86} \mathrm{Kr}$ formation in nuclear reactions induced by the proton bombardment of Pd and $\mathrm{Ag}$ at $0.15,0.6$ (Ag only), 1.05 and $24 \mathrm{GeV}$ using high-sensitivity mass-spectrometry. We then developed a Rudstam-like semi-empirical spallation formula that gives good results in the target and product region of interest. Of over about 500 crosssections compiled for $\mathrm{Y}(Z=39)$ up to $\operatorname{Ag}(Z=47)$ with $5 \leqslant \Delta A \leqslant 40$ and $E_{\mathrm{p}} \geqslant 130 \mathrm{MeV}, 89 \%$ are calculated to better than a factor of 2 . That percentage increases to $96 \%$ when excluding small cross sections $(\sigma \leqslant 0.1) \mathrm{mb}$ and low energies $\left(E_{\mathrm{p}} \leqslant 206 \mathrm{MeV}\right)$. Our formula is suitable for the calculation of unknown $\mathrm{Kr}$ cross-sections in $\mathrm{Mo}, \mathrm{Ru}$ and $\mathrm{Rh}$, the elements that make the main contribution to cosmogenic krypton in iron meteorites.
\end{abstract}

\section{Introduction.}

Spallation is ubiquitous in nature. Solar and galactic cosmic rays interact continuously with interstellar medium, planetary atmospheres, and small bodies in the solar system. Knowledge of spallation reactions is of major interest for astrophysical and cosmochemical problems such as the propagation of cosmic rays in the galaxy and the record of cosmic rays in Solar System matter (see recent reviews by Cesarsky [1] and Reedy et al. [2]). Excitation functions have been measured for only a few reactions and the missing cross sections may be calculated using either mathematical developments of the two-step model [3] or semi-empirical formulae [4, 5]. The latter approach is still the most realistic because it provides generally an experimental to calculated cross-section ratio which is better by a factor of two in well documented target and product mass ranges. In his pioneering work, Rudstam [4] found a five parameter general expression that fitted the data then available. The best agreement was obtained for iron and neighbouring targets. Later Silberberg and Tsao [5] designed a Rudstam-like formula with eleven adjustable parameters that gave, on average, good results in targets lighter than $\mathrm{Cu}$ and was well suited to simulate the propagation of cosmic rays in the Galaxy. The Silberberg and Tsao (or S-T) formula is applicable also in targets heavier than $\mathrm{Cu}$. However, a natural limitation for semi-empirical fits is the number and the variety of experimental data in the target, incident energy and product region where an 
unknown cross-section has to be calculated. For example the above spallation formulae both underestimate the effect of the $\left(A_{\mathrm{t}} / Z_{\mathrm{t}}\right)$ ratio of the target, as illustrated in Chackett and Chackett [6] and Regnier [7].

One of our interests concerns cosmogenic krypton produced by cosmic-ray-induced nuclear reactions near the surface of the Moon and in meteorites. We first examined nuclear reactions in $\mathrm{Rb}, \mathrm{Sr}, \mathrm{Y}$ and $\mathrm{Zr}$, the main targets for producing krypton in the Moon and in stony meteorites [8]. Unmeasured cross sections in $\mathrm{Rb}$ and $\mathrm{Sr}$ were evaluated using newly developed methods for peripherical reactions, rather than semiempirical fits, which do not apply for low $\Delta A(\leqslant 5)$ and low energy ( $\leqslant 150 \mathrm{MeV}$ ) reactions. In the present paper we will examine the case of iron meteorites, in which the main targets responsible for cosmogenic krypton are in the $\operatorname{Zr}(Z=40)$ to $\operatorname{Pd}(Z=46)$ region. We irradiated $\mathrm{Pd}$ and $\mathrm{Ag}$ targets with 0.15 , 0.6 (Ag only), 1.05 and $24 \mathrm{GeV}$ protons and measured cross sections of krypton isotopes with $A=78,80$, $81,82,83,84,85$ and 86 . This new data, plus results from this laboratory for $\mathrm{Y}$ and $\mathrm{Zr}$ [8], cross sections measured by Belyaev et al. [9] in ${ }^{90,91,94} \mathrm{Zr}$, and some others results, enabled us to calculate more accurate parameters of the Rudstam CDMD formula in the $\mathrm{Y}(Z=39)$ to $\mathrm{Ag}(Z=47)$ target region. Our new results and new cross-section formula will permit the calculation of the cosmogenic component of krypton in iron meteorites.

\section{Experimental.}

The techniques employed for the measurement of stable noble gas isotopes in our laboratory have already been described in [7] and [8]. Pure target foils of $\mathrm{Pd}(99.9 \%$ or $3 \mathrm{~N})$ and $\mathrm{Ag}(5 \mathrm{~N})$ were stacked with monitor and guard $\mathrm{Al}(5 \mathrm{~N})$ foils. Exact thickness (about $20 \mu \mathrm{m}$ ) was determined by weighing. The targets were irradiated between 1971 and 1975 in the accelerators of Orsay $(150 \mathrm{MeV}), \mathrm{CERN}-\mathrm{SC}$ $(600 \mathrm{MeV})$, Saturne $1(1.05 \mathrm{GeV})$ and CERN-PS $(24 \mathrm{GeV})$. Internal proton beams were used, except for one irradiation at $24 \mathrm{GeV}$. Proton fluences were measured according to the ${ }^{27} \mathrm{Al}(p, \mathrm{X})^{22} \mathrm{Na}$ monitor reaction whose cross sections are 17.2, 17.3, 15.3 and $10 \mathrm{mb}$, respectively at $0.150,0.600,1.05$ and $24 \mathrm{GeV}$ [10]. At least 2 years after irradiation, Pd or Ag targets and blank foils were melted in an extraction system. Gases were exposed in several steps to $\mathrm{Ti}$ and $\mathrm{CuO}-\mathrm{Pd}$ getters, cooling slowly from 700 to $200{ }^{\circ} \mathrm{C}$ to eliminate active species. The noble gases $\mathrm{He}, \mathrm{Ne}, \mathrm{Ar}$ and $\mathrm{Kr}$ were separated into enriched fractions using charcoal traps. Argon and krypton were successively introduced into a statically operated, $60^{\circ}$-sector, $12 \mathrm{~cm}$ radius mass spectrometer. Calibration was carried out using air standards. The isotope ratios were subjected to corrections for memory or pumping, re-extractions, mass-discrimi- nation, doubly-charged ions, blanks and hydrocarbons.

\section{Results.}

Cross sections for krypton isotopes are reported for $\mathrm{Pd}$ and $\mathrm{Ag}$ targets in tables I and II. All results are averages of two to four independent measurements, weighted by individual errors. Our procedure for calculating the uncertainty takes into account the error on target preparation and impurities, measurement of ${ }^{22} \mathrm{Na}$ in monitoring, blanks and hydrocarbons, doubly-charged ions, zero time corrections to massspectrometer analysis, mass discrimination, re-extraction and calibration. All cross-sections are cumulative. Earlier measurements in $\mathrm{Ag}$ were made by Bieri and Rutsch [11] at $540 \mathrm{MeV}$ and by Hudis et al. [12] with 3 and $29 \mathrm{GeV}$ protons. The $29 \mathrm{GeV}$ results of reference [12] are in very good agreement with ours at $24 \mathrm{GeV}$. Krypton cross-sections at $1.05 \mathrm{GeV}$ are significantly larger than those at $24 \mathrm{GeV}$, strongly suggesting a maximum for most excitation functions around $1 \mathrm{GeV}$. Cross sections for ${ }^{78} \mathrm{Kr}$, ${ }^{82} \mathrm{Kr}$ and ${ }^{84} \mathrm{Kr}$ in $\mathrm{Ag}$ are plotted versus energy on figure 1 , where the lines are excitation functions calculated according to the methods described in the following section.

Table I. - Krypton cross sections (in $\mathrm{mb}$ ) for $\mathrm{Pd}$ targets as a function of the incident energy $E_{\mathrm{p}}$ (in $\mathrm{GeV}$ ).

\begin{tabular}{lcccc}
\hline$E_{p}(\mathrm{GeV})$ & 0.150 & 1.05 & 24 \\
\hline${ }^{78} \mathrm{Kr}$ & $0.0009 \pm 0.0005$ & 15.0 & \pm 1.5 & $8.4 \quad \pm 1.2$ \\
${ }^{80} \mathrm{Kr}$ & $0.0026 \pm 0.005$ & 24.7 & \pm 2.5 & $13.3 \quad \pm 1.5$ \\
${ }^{81} \mathrm{Kr}$ & $0.0032 \pm 0.0012$ & 26.8 & \pm 2.7 & $13.8 \quad \pm 1.4$ \\
${ }^{82} \mathrm{Kr}$ & $0.0060 \pm 0.0006$ & 29.1 & \pm 2.9 & $14.4 \quad \pm 1.4$ \\
${ }^{83} \mathrm{Kr}$ & $0.0106 \pm 0.0011$ & $31.3 \pm 3.1$ & $14.9 \quad \pm 1.5$ \\
${ }^{84} \mathrm{Kr}$ & $0.0017 \pm 0.0005$ & $3.6 \pm 0.4$ & $2.2 \quad \pm 0.2$ \\
${ }^{85} \mathrm{Kr}$ & & $0.057 \pm 0.006$ & $0.054 \pm 0.011$ \\
${ }^{86} \mathrm{Kr}$ & & $0.012 \pm 0.002$ & & \\
\hline
\end{tabular}

Table II. - Krypton cross sections (in mb) for $\mathrm{Ag}$ target as a function of the incident energy $E_{\mathrm{p}}$ (in $\mathrm{GeV}$ ).

\begin{tabular}{lccccccc}
\hline$E_{\mathrm{p}}(\mathrm{GeV})$ & 0.150 & \multicolumn{2}{c}{0.600} & \multicolumn{2}{c}{1.05} & 24 \\
\hline${ }^{78} \mathrm{Kr}$ & $0.0014 \pm 0.0005$ & 4.4 & \pm 0.4 & 12.7 & \pm 1.3 & $8.1 \quad \pm 2.3$ \\
${ }^{80} \mathrm{Kr}$ & $0.8031 \pm 0.0011$ & 8.6 & \pm 0.9 & 20.5 & \pm 2.1 & $12.3 \quad \pm 3.4$ \\
${ }^{81} \mathrm{Kr}$ & $0.0032 \pm 0.0012$ & 10.5 & \pm 1.1 & 22.2 & \pm 2.2 & $12.7 \quad \pm 3.6$ \\
${ }^{82} \mathrm{Kr}$ & $0.0055 \pm 0.0019$ & 12.6 & \pm 1.3 & 23.8 & \pm 2.4 & $13.0 \quad \pm 3.7$ \\
${ }^{83} \mathrm{Kr}$ & $0.0070 \pm 0.0026$ & 15.4 & \pm 1.5 & 25.3 & \pm 2.5 & 13.6 & \pm 3.8 \\
${ }^{84} \mathrm{Kr}$ & & $1.34 \pm 0.13$ & $2.31 \pm 0.23$ & $1.4 \quad \pm 0.4$ \\
${ }^{85} \mathrm{Kr}$ & & $0.0095 \pm 0.0010$ & $0.021 \pm 0.002$ & $0.018 \pm 0.005$ \\
${ }^{86} \mathrm{Kr}$ & & & & & & $0.004 \pm 0.002$
\end{tabular}




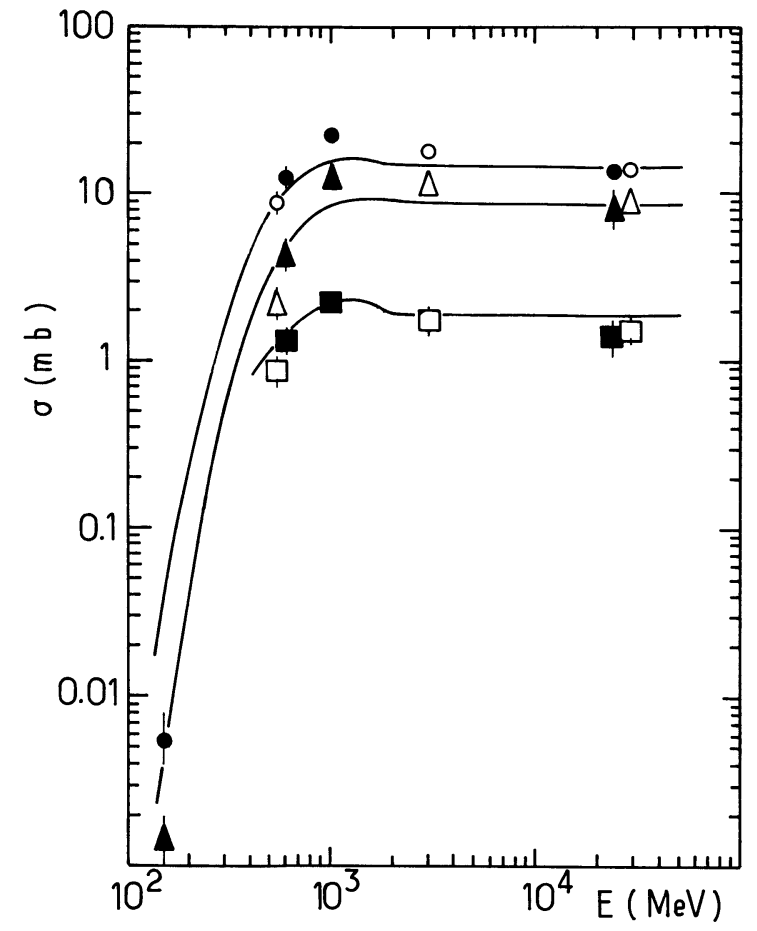

Fig. 1. - Measured cross-sections $\sigma$ in $\mathrm{mb}$ for the production of krypton isotopes ${ }^{78} \mathrm{Kr}$ (triangles) ${ }^{82} \mathrm{Kr}$ (circles) and ${ }^{84} \mathrm{Kr}$ (squares) in silver bombarded with protons of energy $E$ in $\mathrm{MeV}$. Filled symbols : this work; empty symbols : literature values (see text and table III). Solid lines are excitation functions calculated according to our spallation formula.

\section{The cross-section formula between $\mathrm{Y}$ and Ag.}

4.1 Methods. - The Rudstam CDMD formula [4] gives the cross-section $\sigma$ for a reaction product $(Z, A)$ in a target $\left(Z_{\mathrm{t}}, A_{\mathrm{t}}\right)$ according to the following five parameter expression :

$$
\begin{aligned}
& \sigma(Z, A)=K P \exp \times \\
& \quad \times\left[P\left(A-A_{\mathfrak{t}}\right)-R\left|Z-S A+T A^{2}\right|^{3 / 2}\right] .
\end{aligned}
$$

We adopted the same expression for which we calculated new parameters $K, P, R, S, T$, using the least squares and differential corrections methods, well described in [4]. A test for goodness of fit is given by $D$ :

$$
D=\left(\sum_{i=1}^{N} \log \left(\sigma_{i, \mathrm{calc}} / \sigma_{i, \exp }\right)^{2}\right)^{1 / 2}
$$

which has to be a minimum. $N$ is the number of cross-sections used for fitting. Available experimental results are compiled in table III for $\mathrm{Y}, \mathrm{Zr}, \mathrm{Nb}, \mathrm{Mo}$, $\mathrm{Ru}, \mathrm{Pd}$ and $\mathrm{Ag}$ target elements. Only the protoninduced reactions for which $\Delta A=A_{\mathrm{t}}-A$ lies between 5 and 40, and experimental results with less than $40 \%$ uncertainty are considered. Corrections for the monitor cross-section have been applied where necessary according to [10]. Cross sections in $\mathrm{Zr}$ and $\mathrm{Pd}$ were not used for fitting (except in the case of the $K$ parameter) because of the many natural isotopes of these elements. However they will provide an excellent test of the cross-section formula.

The best agreement between the formula and experimental results was obtained in the following way :

i) calculate the five parameters for each line (i.e. each fixed target plus incident energy) of table III ;

ii) weighting by the number of measured crosssections, find the best relation between one chosen parameter and physical constants such as incident energy $E_{\mathrm{p}}, Z, A, Z_{\mathrm{t}}, A_{\mathrm{t}}$ or $A_{\mathrm{t}} / Z_{\mathrm{t}}$. Or, simply take an average value;

iii) start the entire calculation again with one parameter less (successively with 4, 3, 2, 1 parameters).

The parameters were determined in the sequence $S, T, R, P$ and $K$.

4.2 THE PARAMETER $S$. - We found no systematic trend in $S$ with either target, product, or incident energy. Its average value, weighted by the number of cross-sections is :

$$
S=0.489 \pm 0.011 \text { (one standard deviation) }
$$

In the Rudstam formula, $S$ is also constant (0.486) whereas, in the formulae of reference [5] and reference [6], $S$ was found to depend on $A_{\mathrm{t}} / Z_{\mathrm{t}}$.

4.3 The Parameter $T$. $-T$ was found to depend strongly on the target $N / Z$ ratio. The best evidence for this is obtained from the data of Porile and Church [13] in ${ }^{96} \mathrm{Zr},{ }^{96} \mathrm{Mo},{ }^{96} \mathrm{Ru}$ and Belyaev et al. [9] in $90,91,94 \mathrm{Zr}$. Figure 2 shows the average $T$-values obtained in targets, whatever the energy, versus the atomic mass of the target, $A_{\mathrm{t}}$. Clearly, $T$ increases when the target becomes neutron richer. $T$ was fitted by the following equation, where $a_{1}$, $a_{2}, a_{3}$ are constants :

$$
T=a_{1}+a_{2}\left(A_{\mathrm{t}} / Z_{\mathrm{t}}\right)+a_{3} A_{\mathrm{t}}
$$

with

$$
\begin{aligned}
& a_{1}=-1.24 \pm 0.29 \times 10^{-3} \\
& a_{3}=-2.75 \pm 0.76 \times 10^{-6}
\end{aligned}
$$

and

$$
a_{2}=8.42 \pm 0.13 \times 10^{-4} \text {. }
$$

In previous formulae $(4,5,6), T$ had a constant value $\left(3.8 \times 10^{-4}\right)$ in this mass region.

4.4 The PARAMETER $R$. - A simple way to determine $R$ is to consider the cross-section ratio of two reaction products on the same isobar. If the irradiation conditions (projectile, target, incident energy) are the same, 
Table III. - Spallation data for fitting and comparison with 3 semi-empirical formulae.: Because of the numerous natural isotopes of $\mathrm{Zr}$ and $\mathrm{Pd}$, results from these two targets were used for the $K$ determination only. $N_{\mathrm{i}}$ is the number of measured cross-sections for each line. $E$ is the incident proton energy.

\begin{tabular}{|c|c|c|c|c|c|c|}
\hline \multirow[t]{2}{*}{ Target } & \multirow[t]{2}{*}{$E(\mathrm{MeV})$} & \multirow[t]{2}{*}{$N_{1}$} & \multirow[t]{2}{*}{ Reference } & \multicolumn{3}{|c|}{$\left(\sigma_{\text {calc }} / \sigma_{\text {exp }}\right)$ mean $\pm 1 \sigma$} \\
\hline & & & & This work & $\begin{array}{c}\text { Silberberg } \\
\text { and Tsao }\end{array}$ & Rudstam \\
\hline \multirow[t]{11}{*}{${ }^{89}{ }_{Y}$} & 75 & 6 & 8 & $1.22 \pm 0.80$ & $1.6 \pm 0.6$ & $1.6 \pm 0.5$ \\
\hline & 80 & 4 & 14 & $1.48 \pm 1.03$ & $2.1 \pm 1.0$ & $2.0 \pm 0.8$ \\
\hline & 100 & 5 & 15 & $4.68 \pm 1.70$ & $5.6 \pm 4.6$ & $5.3 \pm 3.6$ \\
\hline & 150 & 13 & 8,14 & $2.98 \pm 3.02$ & $3.2 \pm 3.2$ & $2.8 \pm 3.1$ \\
\hline & 168 & 9 & 8 & $1.15 \pm 0.49$ & $1.22 \pm 0.54$ & $1.02 \pm 0.36$ \\
\hline & 180 & 9 & 15 & $1.75 \pm 0.61$ & $1.59 \pm 1.11$ & $1.6 \pm 1.2$ \\
\hline & 200 & 9 & 8 & $0.80 \pm 0.35$ & $1.11 \pm 0.67$ & $0.80 \pm 0.36$ \\
\hline & 240 & 9 & 8,16 & $1.87 \pm 0.85$ & $1.23 \pm 1.09$ & $1.21 \pm 0.67$ \\
\hline & 1050 & 13 & 8 & $0.79 \pm 0.14$ & $1.1 \pm 0.7$ & $0.90 \pm 0.42$ \\
\hline & 2500 & 14 & 8 & $0.94 \pm 0.24$ & $1.7 \pm 1.1$ & $1.49 \pm 0.61$ \\
\hline & 24000 & 12 & 8 & $1.06 \pm 0.29$ & $1.90 \pm 1.06$ & $1.80 \pm 0.80$ \\
\hline \multirow[t]{7}{*}{$\mathrm{Zr}$} & $59 \%$ & 5 & 8 & $0.62 \pm 0.32$ & $1.7 \pm 0.8$ & $1.88 \pm 0.63$ \\
\hline & $75 \%$ & 7 & 8 & $0.78 \pm 0.58$ & $0.88 \pm 0.70$ & $1.19 \pm 0.70$ \\
\hline & $168:$ & 8 & 8 & $1.00 \pm 0.44$ & $1.18 \pm 0.87$ & $0.90 \pm 0.30$ \\
\hline & $200 \%$ & 9 & 8 & $0.87 \pm 0.48$ & $0.89 \pm 0.75$ & $0.82 \pm 0.39$ \\
\hline & $1005 \%$ & 13 & 8 & $0.93 \pm 0.22$ & $0.91 \pm 0.73$ & $0.94 \pm 0.41$ \\
\hline & $2500:$ & 13 & 8 & $0.88 \pm 0.14$ & $1.6 \pm 1.1$ & $1.38 \pm 0.50$ \\
\hline & $24000 \%$ & 12 & 8 & $1.16 \pm 0.23$ & $1.60 \pm 0.63$ & $1.87 \pm 0.73$ \\
\hline${ }^{90} \mathrm{Zr}$ & 1000 & 18 & 9 & $1.41 \pm 0.97$ & $1.5 \pm 0.9$ & $1.26 \pm 0.58$ \\
\hline${ }^{91} \mathrm{Zr}$ & 1000 & 24 & 9 & $1.21 \pm 0.33$ & $1.2 \pm 0.8$ & $1.23 \pm 0.45$ \\
\hline${ }^{94} \mathrm{zr}$ & 1000 & 18 & 9 & $0.92 \pm 0.32$ & $0.94 \pm 0.63$ & $0.96 \pm 0.52$ \\
\hline${ }^{96} \mathrm{Zr}$ & 1800 & 9 & 13 & $1.24 \pm 0.45$ & $0.83 \pm 0.46$ & $1.77 \pm 1.65$ \\
\hline \multirow[t]{4}{*}{${ }^{93} \mathrm{Nb}$} & 240 & 8 & 17 & $5.14 \pm 3.02$ & $1.06 \pm 0.50$ & $1.15 \pm 0.37$ \\
\hline & 320 & 8 & 17 & $5.05 \pm 3.1$ & $1.00 \pm 0.44$ & $1.10 \pm 0.26$ \\
\hline & 500 & 8 & 17 & $3.00 \pm 1.59$ & $0.78 \pm 0.24$ & $0.94 \pm 0.34$ \\
\hline & 720 & 8 & 17 & $1.79 \pm 0.83$ & $0.66 \pm 0.27$ & $0.85 \pm 0.55$ \\
\hline${ }^{96}$ Mo & 1800 & 9 & 13 & $1.11 \pm 0.18$ & $0.73 \pm 0.30$ & $1.05 \pm 0.48$ \\
\hline${ }^{96} \mathrm{Ru}$ & 1800 & 9 & 13 & $1.13 \pm 0.29$ & $0.86 \pm 0.64$ & $1.87 \pm 1.34$ \\
\hline \multirow[t]{2}{*}{ Pd } & $1050 \%$ & 6 & this work & $0.64 \pm 0.11$ & $0.59 \pm 0.14$ & $0.57 \pm 0.07$ \\
\hline & $24000 \%$ & 6 & this work & $1.11 \pm 0.09$ & $1.14 \pm 0.06$ & $1.70 \pm 0.21$ \\
\hline \multirow[t]{8}{*}{$\mathrm{Ag}$} & 540 & 6 & 11 & $1.38 \pm 0.23$ & $0.72 \pm 0.08$ & $0.71 \pm 0.07$ \\
\hline & 600 & 9 & this work & $1.21 \pm 0.62$ & $0.63 \pm 0.24$ & $0.66 \pm 0.32$ \\
\hline & 1050 & 6 & this work & $0.72 \pm 0.10$ & $0.59 \pm 0.07$ & $0.64 \pm 0.14$ \\
\hline & 3000 & 26 & 12,18 & $0.82 \pm 0.15$ & $0.94 \pm 0.19$ & $1.40 \pm 0.57$ \\
\hline & 11500 & 29 & 19 & $1.12 \pm 0.29$ & $1.1 \pm 0.7$ & $1.75 \pm 0.96$ \\
\hline & 24000 & 6 & this work & $1.17 \pm 0.08$ & $1.22 \pm 0.04$ & $1.82 \pm 0.26$ \\
\hline & 29000 & 27 & 12.18 & $1.01 \pm 0.13$ & $1.01 \pm 0.17$ & $1.71 \pm 0.55$ \\
\hline & 300000 & 40 & 20,21 & $1.07 \pm 0.21$ & $0.96 \pm 0.47$ & $1.53 \pm 0.86$ \\
\hline
\end{tabular}

and also if the parameters $K$ and $P$ are independent of $Z$, this ratio is :

$$
\frac{\sigma(Z, A)}{\sigma^{\prime}\left(Z^{\prime}, A\right)}=\frac{\exp \left(-R\left|Z-S A+T A^{2}\right|\right)^{3 / 2}}{\exp \left(-R\left|Z^{\prime}-S A+T A^{2}\right|\right)^{3 / 2}}
$$

$S$ and $T$ are given by equations (3) and (4). Expression (5) applies in the case of cumulative cross sections by just making summations. More than 100 pairs were found for products with $A=72-103$. Finally we agree with Rudstam [4] in that $R$ is independent of the energy $E_{\mathrm{p}}$ and slightly decreases with the atomic number, $A$, of the spallation product in our mass range. However $R$-values were rather scattered around the simple function that best represented them :

$$
R=b_{1} A+b_{2}
$$

with $b_{1}=(-1.71 \pm 0.63) \times 10^{-2}$ and $b_{2}=2.66 \pm 0.52$.

For comparison $R=11.8 A^{-0.45}$ in previous for- 


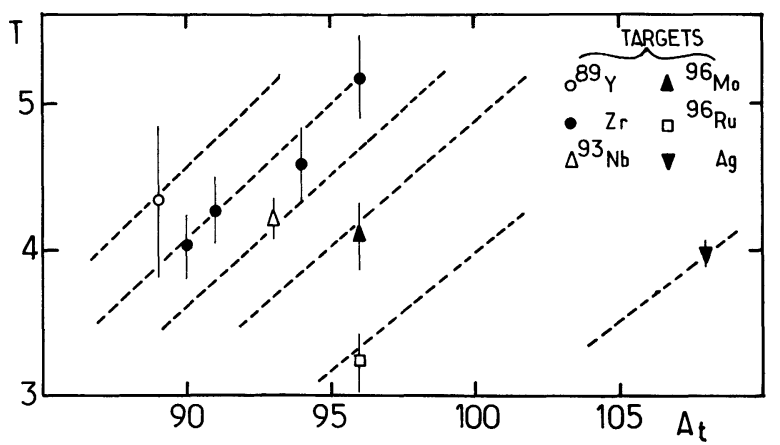

Fig. 2. - Parameter $T$ (in units of $10^{-4}$ ) versus target atomic mass $A_{\mathrm{t}}$. Average $T$-values are quoted for several targets. The $\left(A_{\mathrm{t}}-Z_{\mathrm{t}}\right) / Z_{\mathrm{t}}$ dependence clearly appears from the fitted $T$-values in ${ }^{90,91,94,96} \mathrm{Zr}$ and in ${ }^{96} \mathrm{Zr}$, ${ }^{96} \mathrm{Mo},{ }^{96} \mathrm{Ru}$.

mulae $(4,5)$. The simple shape of equation (6) best represents the data and it applies only in our target and product mass region.

4.5 The PARAMETER $P$. - The parameter $P$ decreases strongly with increasing energy $E_{\mathrm{p}}$, then becomes roughly constant if $E_{\mathrm{p}} \geqslant 1966 \mathrm{MeV}$ as plotted in figure 3 . The best fit is given by :

$$
\begin{array}{lll}
P=c_{1} E^{-c_{2}} & \text { if } & E<E_{0} \\
P=c_{3} & \text { if } & E \geqslant E_{0}
\end{array}
$$

with $c_{1}=91.8 \pm 9.2 ; c_{2}=1.09 \pm 0.08 ; c_{3}=0.023 \pm$ 0.006 and $E_{0}=1966 \mathrm{MeV}$.

No $A_{\mathrm{t}}$ dependence was detected.

The parameter $P$ from Rudstam (4) is also plotted in figure 3 (dashed line) for comparison. The curve from Silberberg and Tsao [5] would be intermediary. However a strict comparison is not possible because we already fixed $S, T$ and $R$. Also the data selection is very important for this parameter.

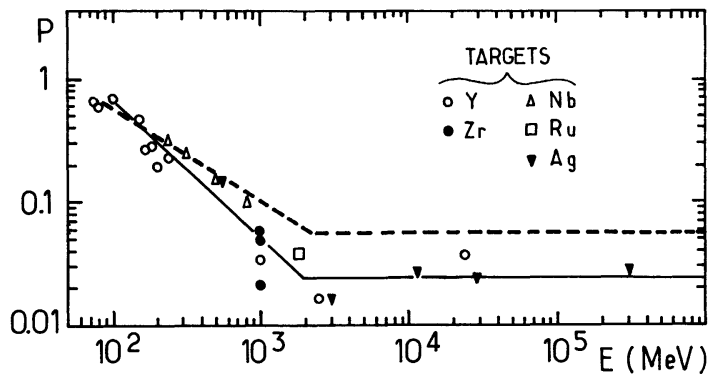

Fig. 3. - Parameter $P$ versus energy. The solid line is the fit given by equations (7) and (8). The dashed line is given by the Rudstam formula.

4.6 The PARAmeter $K$. - We considered $K$ to be a normalizing parameter and looked for a simpler form of equation (23) in reference [4] :

$$
K=f(E) \frac{d_{1}\left(1-d_{2} A_{\mathrm{t}}\right)}{1-d_{3} / P A_{\mathrm{t}}+d_{4} \exp \left(-P A_{\mathrm{t}}\right)} .
$$

Fitting over 426 cross-section data we found :

$$
\begin{array}{lll}
d_{1}=1645 & d_{2}=0.0054 \\
d_{3}=0.46 & d_{4}=0.85 .
\end{array}
$$

An adjustement parameter $f(E)$ was necessary at low energy :

$$
\begin{array}{lll}
f(E)=1 & \text { if } & E>E^{\prime} \\
f(E)=\exp \left(e_{1}-e_{2} E\right) & \text { if } & E \leqslant E^{\prime}
\end{array}
$$

with

$$
\begin{aligned}
& e_{1}=2.22 \quad \pm 0.30 \\
& e_{2}=0.0108 \pm 0.0017 \\
& E^{\prime}=206 \mathrm{MeV}
\end{aligned}
$$

\section{Discussion.}

5.1 COMPARISON WITH EXPERIMENT. - After the calculation of the parameters of our new formula was completed, we found 23 cross-sections that were missed in our first survey of literature. These crosssections were measured in $\mathrm{Nb}$ [22], Mo [23] and $\mathrm{Ag}$ [24]. We also included all measured cross sections in multiple-isotope-targets $\mathrm{Zr}$ and $\mathrm{Pd}$. The final data set available to compare calculated and measured cross-sections was comprised of 491 measurements in $\mathrm{Y}, \mathrm{Zr}, \mathrm{Nb}, \mathrm{Mo}, \mathrm{Ru}, \mathrm{Pd}$ and $\mathrm{Ag}$ targets for products with $5 \leqslant \Delta A \leqslant 40$ and $E_{\mathrm{p}} \geqslant 130 \mathrm{MeV}$. The ratio of calculated to experimental cross sections lies

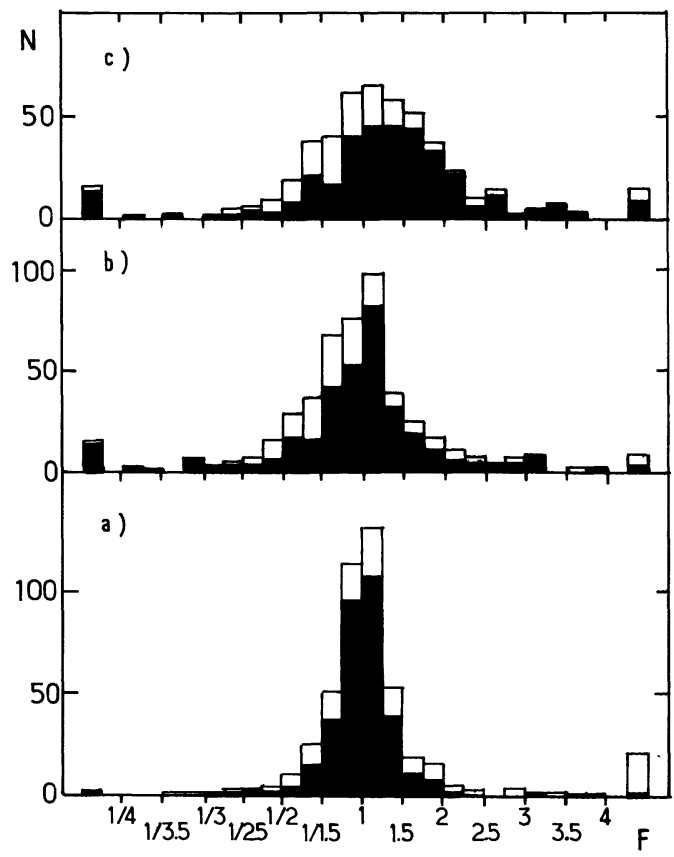

Fig. 4. - Histograms giving the number of cases $N$ when the ratio $F$ of calculated to experimental cross-sections lies between fixed values. In the dark portion, the energy range is limited to $E \geqslant 1 \mathrm{GeV}$. Figure $4 \mathrm{a}$ ) : This work; $4 \mathrm{~b})$ : Silberberg and Tsao formula. 4c) : Rudstam formula. 
within a factor of 1.5 from unity in $72 \%$ of all cases, and within a factor of 2 from unity in $89 \%$ of all cases (compared to $46 \%$ and $76 \%$ respectively for the original Rudstam formula and $57 \%$ and $79 \%$ for the S-T formula). When looking only at $E_{\mathrm{p}} \geqslant$ $1000 \mathrm{MeV}$, these numbers become $83 \%$ and $96 \%$ (43\% and $74 \%$ for Rudstam, $61 \%$ and $80 \%$ for S-T). The ratios from this work, from Silberberg and Tsao [5], and from Rudstam [4] are also represented on the histograms of figures $4 \mathrm{a}, 4 \mathrm{~b}$ and $4 \mathrm{c}$, respectively. These histograms show clearly the advantage of our local formula in the $Z_{\mathrm{T}}=39$ to 47 target region, with a distribution well peaked around unity, almost symmetrical, and much narrower than the two other distributions. A comparison between the three calculations can also be made in table III, where the mean ratio is quoted for each target and each incident energy. In many cases our formula provides a better mean ratio and a better $1 \sigma$ value.

5.2 Evaluation of the calculations. - Among all available cross sections in $\mathrm{Y}$ to $\mathrm{Ag}$ targets, 51 (about $10 \%$ ) are calculated to a worse than 2 factor; 24 of these 51 are less than $0.1 \mathrm{mb}$ cross-sections. In fact almost all cross-sections less than $0.1 \mathrm{mb}$ are overestimated by our formula, which is not generally the case in the work of Rudstam [4] or Silberberg and Tsao [5]. We attribute this fact to the low weight of small cross-sections in our compilation. No systematic trend could be found among the other miscalculated cross-sections. Most cross-section measurements from reference [16] in $\mathrm{Y}$ at $150 \mathrm{MeV}$ give bad ratios.

Looking now at all the results, there is no systematic trend favoring neutron-rich or neutron-poor products. Also, from the data set available, there is no $\Delta A$ effect, at least if $\Delta A \geqslant 5$. However there exists an energy effect in the $\mathrm{GeV}$ region : the formula does not account for a maximum followed by a decrease of excitation functions around $1 \mathrm{GeV}$. Consequently the average ratio is significantly higher at $24 \mathrm{GeV}$ than at 1 or $2.5 \mathrm{GeV}$.

From the work of Belyaev et al. [9], many independent cross-sections for rubidium isotopes with $A=75-90$ were measured in 3 different isotopic targets of zirconium $(A=90,91$ and 94$)$ bombarded with $1 \mathrm{GeV}$ protons. These data are plotted on figure 5 together with our calculations (solid lines) and those of reference [4] (broken lines) and reference [5] (dotted lines). Our formula accounts for the displacement of the mass-distribution toward the neutron rich side when the target becomes neutron richer from ${ }^{90} \mathrm{Zr}$ to ${ }^{94} \mathrm{Zr}$. The Rudstam formula gives constant values, whereas the Silberberg and Tsao formula also predicts the displacement.

The mass-yield curves have been plotted on figure 6 for the spallation of silver. Experimental (sharp) lines were taken from Katcoff et al. [18] at 3 and $29 \mathrm{GeV}$. Calculated (thick) lines clearly show the

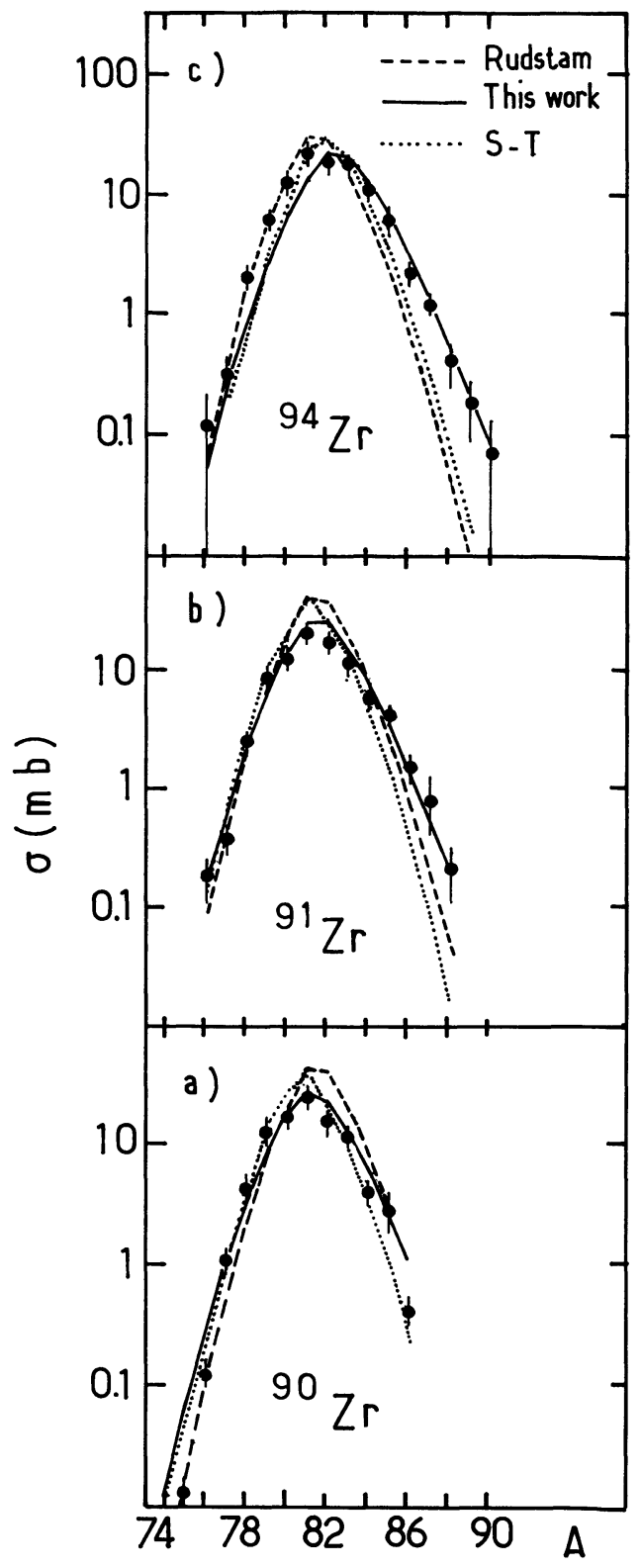

Fig. 5. - Mass-distribution of rubidium isotopes produced in the proton bombardment at $1 \mathrm{GeV}$ of a) ${ }^{90} \mathrm{Zr}$, b) ${ }^{91} \mathrm{Zr}$, and c) ${ }^{94} \mathrm{Zr}$. Solid lines are calculated from this work, dotted lines from Silberberg and Tsao and dashed lines from Rudstam. All experimental cross sections $\sigma$ are from Belyaev et al. [9].

advantage of our formula : the calculated massyield curve from this work at energies $\geqslant 3 \mathrm{GeV}$ is parallel to both experimental curves at 3 and $29 \mathrm{GeV}$ and almost identical to the experimental curve at $29 \mathrm{GeV}$. The Rudstam formula does not account for the slope of the mass-yield curve and the S-T formula gives oscillations that are not evident from experiment.

5. 3 COSMOGENIC KRYPTON IN IRON METEORITES. The most abundant krypton-producing target elements in iron meteorites are $\mathrm{Mo}, \mathrm{Ru}, \mathrm{Rh}$ and $\mathrm{Pd}$. 


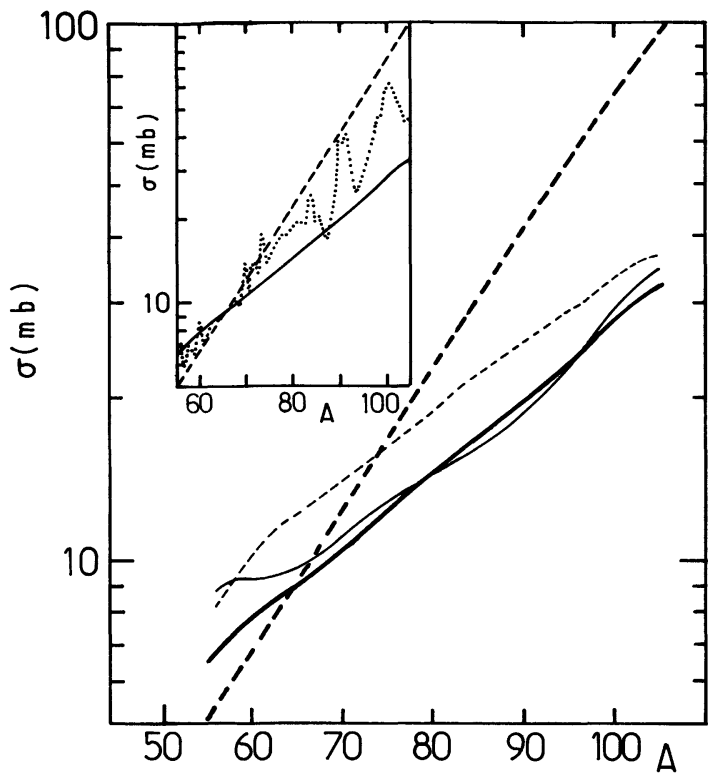

Fig. 6. - Mass yield curves in silver at several proton energies. Sharp lines are experimental and adopted from reference [18] at $3 \mathrm{GeV}$ (dashed line) and $29 \mathrm{GeV}$ (continuous line). Thick lines are calculated at $4 \mathrm{GeV}$ from our formula (continuous line) and the Rudstam formula (dashed line). The reduced figure on the left corner shows the same calculated mass yield curves together with that of the S-T formula (dotted line).

Both $\mathrm{Mo}$ and $\mathrm{Ru}$ have $\Delta A$ values for $\mathrm{Kr}$ isotopes which are intermediate between the $\mathrm{Y}-\mathrm{Zr}$ and $\mathrm{Pd}-\mathrm{Ag}$ target groups, and mainly particles of more than $200 \mathrm{MeV}$ are expected to be efficient from threshold considerations. We thus have a good case for the calculation of unknown cross-sections for ${ }^{78-84} \mathrm{Kr}$ in $\mathrm{Mo}$ and $\mathrm{Ru}$ using our semi-empirical formula. However, we particularly scrutinized the ratio of calculated over measured cross sections for $\mathrm{Kr}$ isotopes in $\mathrm{Y}, \mathrm{Zr}, \mathrm{Pd}$ and $\mathrm{Ag}$ targets, in order to define any poor trends more precisely. Looking for absolute values in the case of ${ }^{82} \mathrm{Kr}$, and for isotopic ratios ${ }^{i} \mathrm{Kr} /{ }^{82} \mathrm{Kr}$ otherwise, we obtained the results of table IV (mean values over several energies for each target, and over all targets and energies). Errors are one standard deviation from the mean. Whatever the target, the formula tends to underestimate, by about $15 \%$, both absolute cross sections and the ${ }^{78} \mathrm{Kr} /{ }^{82} \mathrm{Kr}$ ratio. Also the ${ }^{84} \mathrm{Kr} /{ }^{82} \mathrm{Kr}$ ratio is always overestimated by about $30 \%$. Consequently, some normalizing procedure should be applied when using krypton excitation functions to calculate cosmogenic krypton in extraterrestrial matter [25].
Table IV. - Calculated over experimental cross-sections or isotopic ratios for $\mathrm{Kr}$ isotopes in $\mathrm{Y}, \mathrm{Zr}, \mathrm{Pd}$ and Ag targets at several proton bombarding energies. The last column averages all ratios. Experimental data for $\mathrm{Y}$ and $\mathrm{Zr}$ are from reference [8], and for $\mathrm{Pd}$ and $\mathrm{Ag}$ are from this work and reference [12]. ${ }^{85} \mathrm{Kr}$ is not included in the comparison because it has an isomer that does not decay through internal transition.

\begin{tabular}{lccccc}
\hline & $Y$ & $\mathrm{Zr}$ & $\mathrm{Pd}$ & $\mathrm{Ag}$ & $\begin{array}{l}\text { All targets } \\
\text { and energies }\end{array}$ \\
\hline $78 / 82$ & $0.73 \pm 0.20$ & $0.81 \pm 0.10$ & $0.90 \pm 0.02$ & $1.03 \pm 0.20$ & $0.85 \pm 0.20$ \\
$80 / 82$ & $0.91 \pm 0.12$ & $0.97 \pm 0.07$ & $1.01 \pm 0.03$ & $1.04 \pm 0.09$ & $0.97 \pm 0.10$ \\
$81 / 82$ & $0.93 \pm 0.09$ & $1.00 \pm 0.05$ & $1.02 \pm 0.01$ & $1.07 \pm 0.04$ & $1.00 \pm 0.08$ \\
$83 / 82$ & $1.04 \pm 0.21$ & $1.02 \pm 0.08$ & $1.00 \pm 0.01$ & $1.03 \pm 0.05$ & $1.03 \pm 0.13$ \\
$84 / 82$ & $1.3 \pm 0.9$ & $1.5 \pm 0.8$ & $1.30 \pm 0.22$ & $1.27 \pm 0.10$ & $1.35 \pm 0.61$ \\
\hline $82 \mathrm{Kr}$ & $0.91 \pm 0.17$ & $0.83 \pm 0.19$ & $0.85 \pm 0.35$ & $0.89 \pm 0.19$ & $0.88 \pm 0.19$
\end{tabular}

Preliminary calculations (25) yielded a reasonable agreement, often better than $10 \%$, for the krypton isotopic distribution in some iron meteorites.

\section{Conclusion.}

Cross-sections for ${ }^{78-86} \mathrm{Kr}$ were obtained in Pd and $\mathrm{Ag}$ targets bombarded with protons of $0.15,1.05$ and $24 \mathrm{GeV}$. Excitation functions pass through a maximum around $1 \mathrm{GeV}$. We calculated new parameters that appreciably improve the Rudstam formula in the $\mathrm{Y}$ to Ag target region. The new semi-empirical formula is expected to calculate unknown cross-sections to better than a factor of 1.5 in most cases, providing that $5 \leqslant \Delta A \leqslant 40, E_{\mathrm{p}}>206 \mathrm{MeV}$, and $\sigma>0.1 \mathrm{mb}$. Less than $4 \%$ of such data were found to give a fit that was worse than a factor of two. That number increases to $11 \%$ when looking at all data with $5 \leqslant \Delta A \leqslant 40$ and $E \geqslant 130 \mathrm{MeV}$. This work will be used to calculate the cosmogenic component of krypton in iron meteorites, a sensor of irradiation effects in the Solar System.

\section{Acknowledgments.}

We thank G. N. Simonoff for his continuous support of this work, F. Baros and R. C. Reedy for useful discussions, J. Letaw for providing results from the last version of the S-T formula, A. Mackenzie Peers for improving the English text, and the accelerator teams of Orsay, Saturne and CERN for their cooperation. Valuable technical assistance was provided by $\mathrm{F}$. Brout and C. Chouard. The research was sponsored by the Centre National de la Recherche Scientifique (E.R.A. 144 et A.T.P. Planétologie). 


\section{References}

[1] Cesarsky, C. J., Ann. Rev. Astron. Astrophys. 18 (1980) 289.

[2] Reedy, R. C., Arnold, J. R., Lal, D., Science 219 (1983) 127.

[3] Bertini, H. W., in Spallation Nuclear Reactions And Their Applications, Shen, Merker, Eds, 1976, p. 27.

[4] Rudstam, G., Z. Naturf. 21a (1966) 1027. To our knowledge, the CDMD formula is the most widely used. Also it gives slightly better results than the CDMD-G formulation in our mass region.

[5] Silberberg, R., Tsao, C. H., Astrophys. J. Supp. 220 (1973) 315. Improvements of the Silberberg and Tsao spallation formula were published in Spallation Nuclear Reactions And Their Applications, Shen, Merker, Eds, 1976, p. 49 and later in Proceed. 16th Int. Cosmic. Ray Conf., Kyoto, 1979, p. 202.

[6] Chackett, K. F., Chackett, G. A., Nuclear Physics A 100 (1967) 633.

[7] Regnier, S., Phys. Rev. C 20 (1979) 1517.

[8] Regnier, S., Lavielle, B., Simonoff, M., Simonoff, G. N., Phys. Rev. C 26 (1982) 931.

[9] Belyaev, B. N., Domkin, V. O., Egorov, Y. S., Korobulin, Y. G., KaIzhanskiI, L. M., Bull. Acad. Sci. USSR, Phys. Ser. 42 (1978) 151 translated from Iz. Akad. Nauk SSSR, Ser. Fiz. 42 (1978) 2392.

[10] Tobailem, J., De Lassus St Genies, C. H., Leveque, C., Report CEA-N-1466 (1), 1971.

[11] Bieri, R. H., Rutsch, W., Helv. Phys. Acta 35 (1962) 553.
[12] Hudis, J., Kirsten, T., Stoenner, R. W., Schaeffer, O. A., Phys. Rev. C 1 (1970) 2019.

[13] Porile, N. T., Church, L. B., Phys. Rev. 133 (1964) B 310 .

[14] Regnier, S., Thesis 557 (1977) Bordeaux.

[15] Caretto, A. A., Wiig, E. D., Phys. Rev. 115 (1969) 1238.

[16] Caretto, A. A., WiIg, E. O., Phys. Rev. 103 (1956) 236.

[17] Korteling, R. G., Hyde, E. K., Phys. Rev. 136 (1964) B 425 .

[18] Katcoff, S., Fickel, H. R., Wyttenbach, A., Phys. Rev. 166 (1968) 1147.

[19] English, G., Porile, N. T., Steinberg, E. P., Phys. Rev. C 10 (1974) 2268.

[20] English, G., Yu, Y. W., Porile, N. T., Phys. Rev. $C 10$ (1974) 2281.

[21] Porile, N. T., Cole, G. D., Rudy, C. R., Phys. Rev. C 19 (1979) 2288.

[22] Katcoff, S., Cumming, J. B., Gobel, J., Buchaman, V. J., Susskind, H., Hsu, C. J., Nucl. Instrum. Methods 129 (1975) 473.

[23] Erdal, B. R., Grant, P. M., Casella, V. R., Ogard, A. E., O'Brien, H. A., Nuclear Cross Sections And Technology, N.B.S. Special Publication 425 (1975) 492.

[24] Panontin, J. A., Porile, N. T., Caretto, A. A., Phys. Rev. 165 (1968) 1273.

[25] Lavielle, B., Regnier, S., 46th Meeting of the Meteoritical Society, Mainz (1983), abstract, to be published in Meteoritics. 